\title{
Ebru Boyar and Kate Fleet (ed.), Ottoman Women in Public Space, Leiden-Boston: Brill, 2016, xi+294 S. ISBN: 978-900-4316-43-0
}

\author{
Fatma Erdim ${ }^{1}$ (1)
}

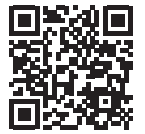

'Sorumlu yazar/Corresponding author: Fatma Erdim (Araş. Gör.),

İstanbul Üniversitesi, Edebiyat Fakültesi, Tarih Bölümü, İstanbul, Türkiye

E-posta: fatma.erdim@istanbul.edu.tr ORCID: 0000-0003-1389-3488

Başvuru/Submitted: 15.07.2020

Kabul/Accepted: 08.09.2020

Atıf/Citation: Erdim, Fatma, "Boyar, Ebru and Fleet, Kate, Ottoman Women in Public Space, Leiden-Boston: Brill, 2016" (Kitabiyat). GüneyDoğu Avrupa Araştırmaları Dergisi, 34 (2020), s. $119-124$

https://doi.org/10.26650/gaad.20213405

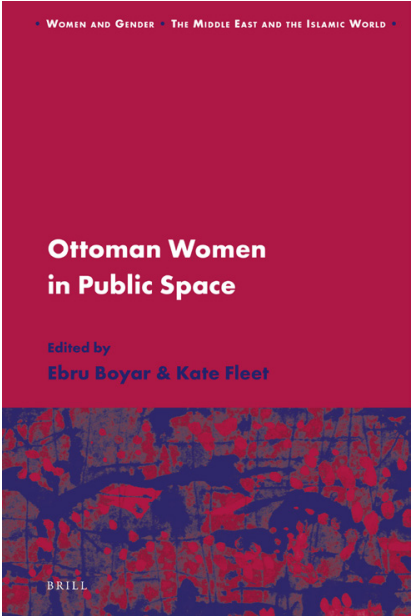


Osmanlı coğrafyasında yaşayan kadınları oryantalist bir bakışla tasvir eden yaklaşımların eleştirilmeye başlandığı ve birincil kaynaklara dayalı olarak yapılan çalışmalar ışığında nispeten bağımsız, kendi mülkiyetini kontrol eden, ekonomik ve sosyal meselelerle aktif olarak ilgilenen Osmanlı kadınlarının varlığının literatürde bir yere oturduğu söylenebilir. Bu yeniden değerlendirmelere rağmen Osmanlı kadınlarının büyük ölçüde eş ve anne olarak rolleri üzerinde durulmakla yetinildiğine, kamusal alanın aktif katılımcıları ve gündelik hayatın ayrılmaz parçaları olarak ele alan akademik çalışmaların ise yakın zamanlara kadar cılız kaldığına kanaat getirmek zor değildir. Bu konudaki yaygın kanaatlerin yeniden değerlendirilmesine katkıda bulunan ve Osmanlı kadınlarının kamusal alandaki varlığı üzerine editoryal bir derleme olan Ottoman Women in Public Space, Cambridge Üniversitesi Skilliter Osmanlı Çalışmaları Merkezi'nde (The Skilliter Centre for Ottoman Studies) yapılan bir araştırma projesinin ürünüdür. Söz konusu projeye Osmanlı kadınlarının kamusal alandaki görünmezliğini ortaya koyma gayesiyle başlanmış olsa da, projenin boyutu Osmanlı kadınlarının kamusal alandaki görünürlüğü yönünde ve imparatorluğun tüm dönemlerini kapsayacak şekilde değişir. Bu kitapta farklı dönemler ve konular üzerinde ihtisaslaşan araştırmacılar tarafından belirlenen konular gazeteler, hatıratlar, seyahatnameler, arşiv belgeleri ve edebî eserler gibi birincil kaynaklar literatürle birlikte değerlendirilerek ele alınıyor. Palmira Brummett, Svetla laneva, Kate Fleet, Edith Gülçin Ambros ve Ebru Boyar'ın katkılarıyla hazırlanan ve sekiz bölümden oluşan kitabın ilk bölümü ise bütün yazarlar tarafından ortak kaleme alınıyor.

Kitabın müşterek yazılan "Ottoman Women in Public Space: An Introduction” (s. 1-17) başlıklı ilk bölümünde kamusal alanın ne olduğu üzerine kafa yoran yazarlar, kamusal alan ve özel alan arasındaki sınırın muğlaklığının farkındadırlar. Daha fazla görünür olmanın görünürlük sıklığıyla ilişkilendirilmemesi gerektiği, kalabalıklar arasındaki fakir kadınların "görünmez" bir kitleyi temsil ederken; gücün, servetin ve ihtişamın tecessüm ettiği zengin kadınların daha görünür oldukları görüşündedirler. Kadınların yaşının kamusal alandaki görünürlük düzeylerini etkilediği ve yaşı ilerlemiş kadınların daha görünür oldukları noktasında da hemfikirdirler. Yaygın kanaatin aksine, kırsal kesimlerdeki kadınların tarım ve hayvancılık alanlarındaki işleri nedeniyle şehirlerdeki kadınlardan daha görünür olduklarını dile getirirler. İlginç bir husus ise kadınların kamusal alanda sadece görsel olarak değil, aynı zamanda sesleriyle ve hatta kokularıyla da var olduklarının üzerinde durmalarıdır. Bunların yanı sıra Osmanlı toplumunda yaşayan bir kadının kamu yararına inşa ettirdiği vakıf binalarıyla gündeme gelebileceği gibi, iffetsizlik gibi olumsuz ithamlarla da de facto olarak kamusal alanda varlık gösterebileceğine değinirler (s. 6-12).

Palmira Brummett “The 'What If ?' of the Ottoman Female: Authority, Ethnography, and Conversation" (s. 18-47) başlığını taşıyan ikinci bölümde seyahatnamelerden ve yabancı gözlemcilerin yazdıklarından hareketle, erken modern dönemde yaşayan Osmanlı kadınlarının seçeneklerinin ve rollerinin algılanma ve sunulma biçimlerine değinerek Osmanlı kadınları hakkında mevcut algıların ötesinde bazı varsayımlarda bulunur. Bu varsayımlar üzerinden 
kadınların eylemlerinin ve toplumun geleneklerinin tarihî temellerini durumlara ve anlatılara göre incelemeyi önerir. Brummett'e göre Avrupa'dan gelen erkek seyyahların anlatıları 16. ve 17. yüzyıl Osmanlı kadınlarını hem hayalî hem de kendi gözlemlerine dayalı olarak resmeder. Osmanlı kadınları hakkındaki en temel kaynakları erkekler olan Avrupalı gözlemcilerin Osmanlı kadınlarını aktif, hareketli, şan ve şöhret peşinde koşan varlıklar olarak tasavvur ettiklerini belirtir. Bu anlatılarda Avrupa'da olduğu gibi hanım sultanların hane politikalarına aktif bir şekilde katıldıkları ifade edilir. Arka plandaki kadınlar ile valide sultan gibi ön plandaki kadınlar, sokak kedilerini besleyen, sohbet eden, gözlemleyen ve yemek pişiren kadınlar bu anlatılarda bir aradadır (s. 33- 42). Bu anlatılardan yola çıkan Brummett, erken modern Osmanlı toplumunda kadınların erkeklerle sohbet etme durumunun düşünülenden daha yaygın olduğunu ileri sürmektedir.

Svetla laneva "Female Actors, Producers and Money Makers in Ottoman Public Space: The Case of the Late Ottoman Balkans" (s. 48-90) başlıklı üçüncü bölümde Osmanlı kadınlarının kamusal alandaki başlıca rollerinin ekonomik olduğu varsayımından yola çıkarak, hem kentsel hem de kırsal alanda ekonomik aktörler olarak mevcudiyetleri ve görünürlükleri üzerinde durur. 19. yüzyıl Balkan coğrafyasına odaklanan yazar, Osmanlı kadınlarının hayır işlerindeki ve diğer sosyo-ekonomik işlerdeki rollerine değinerek ekonomik alanda pasif oldukları yönündeki yaygın ve basmakalıp görüşlere karşı çıkar. Bunu yaparken Osmanlı kadınlarının fabrikalarda üretime katılarak aslında sanayileşmenin en önemli süreçlerinden birine katkıda bulunduklarını da görmemizi sağlar (s. 66). laneva'ya göre Osmanlı kadınlarının zenginliği toplumdaki yerlerini belirleyen faktörlerden birisidir. Buna göre zenginliğini kamu yararına kullananların toplumsal saygınlığı ve kamusal görünürlüğü artmaktadır. Osmanlı kadınlarının dinî ve kamusal tesislerin sponsorları olduklarından bahsetmekle birlikte, içlerinden çok azının vakıfların idarecileri olduklarından, genelde haklarını erkek vekillere devrettiklerinden söz eder. Eşlerinin ve babalarının sosyal statüleri de kadınların toplumdaki yerini belirlediği için Osmanlı İmparatorluğu'nun son dönemlerinde bile avantajlı evliliklerin kadınların sosyal konumunu etkilemeye devam ettiğinden bahseder (s. 82-87). Sonuçta çalışan veya servet sahibi kadınların sosyal ve ekonomik hayatın içerisinde aktif olarak yer aldıklarını, Avrupamerkezci bakış açısının aksine kadınların aile bütçesine katkı sağlamalarının Osmanlı toplumu için sıra dışı bir durum olmadığını da vurgular.

Kitapta yer alan “The Powerful Public Presence of the Ottoman Female Consumer" (s. 91-127) başlıklı dördüncü bölümde Kate Fleet, tüketici ve tüketimin itici gücü olarak Osmanlı kadınlarını ele alır. Zengin kadınların genelde fiziksel varlıklarıyla değil itibarlarıyla kendilerini görünür kıldıklarından söz eder. Fleet'in belirttiğine göre 16. yüzyılda İstanbul'da kadınları kahve veya tütün içerken ve sıklıkla da kaymakçı dükkanlarına giderken görmek mümkündür. Öyle ki kadınların kaymakçı dükkanlarında mahrem olmayan erkeklerle buluşmaları, kamusal alanda tütün ve kahve içmeleri şikâyet konusu olur (s. 92-98). Çalışmanın devamında Fleet protesto eden kadın tüketicilerden de bahseder. Örneğin 1789'da ekmek kıtlığından muzda- 
rip kadınlar fırınların önünde bu durumu protesto eder. Yine 1808'de artan fiyatlara öfkelenen kadınlar o sırada öğle yemeğini yemekte olan İstanbul kadısının evini basarlar. Kadı ortamı terk edince oradan ayrılarak ellerinde ucunda mumların, kokmuş ciğer ve bağırsakların takılı olduğu sırıklarla cuma namazına gitmekte olan dönemin padişahı IV. Mustafa'nın yolunu keserler (s. 103-106). Bunların yanı sıra Fleet, değişen modanın ve zevklerin farkında olan, modern pazarın şekillenmesinde tüketici olarak aktif rol oynayan ve 19. yüzyıldaki değişimlerle daha net bir şekilde gözlemlenen “yeni Osmanlı kadını”ı tarif eder (s. 119). 19. yüzyıla gelindiğinde kadınlara özel pazarların gelişmeye başladığını, sadece kadınlara açık restoranların, pastanelerin, terzihanelerin ve fotoğraf stüdyolarının işletildiğini belirtir (s. 125-126). Fleet'e göre hane halkının tüketiminde önemli rolü olan kadınlar erkek satıcılar için de hedef müşteri kitlesidir. Bu nedenle kadınların tüketim dünyasını aktif olarak şekillendirmeleri ve pazarlardaki görünürlüğü, çalışmasının bel kemiğini oluşturmaktadır.

Yine Fleet tarafından kaleme alınan "The Extremes of Visibility: Slave Women in Ottoman Public Space” (s. 128-149) başlıklı diğer bölümde Osmanlı toplumunda sosyal ölçekte en yüksek seviyeden en düşük seviyeye kadar rol alabilen ve ilk bakışta hür kadınlardan kolayca ayırt edilemeyen köle kadınların kamusal alandaki görünürlükleri incelenmektedir. Fleet kadın kölelerin kamusal alandaki mevcudiyetleri bakımından Osmanlı toplumu için bir istisna teşkil ettiklerine ve diğer kadınlar için tasavvur edilemeyecek bir düzeyde kamusal görünürlüğün varlığına dikkat çeker. Bunu yaparken önce köle kadınların rollerine bakarak görünürlük biçimlerini ve düzeylerini ele alır. Ardından ise onları emtia ve mülkiyet olarak ayrı kategorilerde değerlendirir. Her şeyden önce emtia olarak kabul edilen köle kadınları sıklıkla köle tacirleri tarafından esir pazarlarına götürülürken ve imparatorluk topraklarında ev sahibelerine eşlik ederlerken görmek mümkündür. Böylece köle sahibi varlıklı kadınlar hem daha kolay ve daha özgür dolaşma imkânı yakalarken hem de statüleri halk nezdinde daha somut hale gelir (s. 129-132). Fleet'in burada öne çıkan iddiası köle kadınların, sahiplerinin onlara bir mülkiyet ya da emtia olarak bahşettikleri onurla görünür olduklarıdır. Bu durumda köle kadınların hane halkına bağı olarak onur sahibi olabileceğinden, sahibinin onuruyla korunabileceğinden, fuhuş işçisi olarak çalıştırılabileceğinden veya bir borcun karşılığında rehin olarak teslim edilebileceğinden bahseder (s. 149). 19. yüzyıl romanlarına sıkça atıfta bulunan Fleet'e göre bu onur eksikliği ve sahibinden bahşedilecek onura olan bağımlılık köle kadınları, hür kadınlardan farklı olarak kolay ifşa edilebilir konuma getirmektedir.

Edith Gülçin Ambros “Frivolity and Flirtation” (s. 150-186) başlığını taşıyan altıncı bölümde Osmanlı İmparatorluğu sınırları içerisinde kadınların erkeklerle kamusal alandaki flört yasağı ile pratikteki gerçeklik arasındaki tutarsızlığı edebî eserlerden yola çıkarak ortaya koymayı amaçlar. Edebî eserlerin ya söze dayalı olduklarını ya da erkeklerin kaleminden çıktıklarını belirterek bu kaynaklardaki anlatıların tek taraflı bakış açısı sunma veya tamamen erkeklerin fantezisini yansıtma ihtimalini metodolojik bir problem olarak görür. Bu nedenle geleneksel olarak daha çok kadınlar tarafından söylenegelen manilerin yanı sıra, hayatı ve gerçeği yan- 
sıtan anonim halk türkülerini de kullanarak kaynaklarını çeşitlendirir. Aynı şekilde seyahat yazılarında ve sosyal mizaha dayalı eserlerde yer alan davranışlara da değinir. Edebî şiirin genellikle şehirde yaşayan kadınları ele aldığını ve anonim olduğunu; halk şiirinin ise köyde yaşayan kadınları konu edindiğini, onların davranışlarına ve bazen de isimlerine yer verebildiğini belirtir. Herhangi bir döneme ya da bölgeye odaklanmadığı çalışmasında sadece Türkçe yazılmış eserlerden yararlanan yazar, İstanbul ve Anadolu üzerine yoğunlaşmak durumunda kalır. Flört etme fırsatı sunan toplanma yerleri üzerinde dururken kadınların yarı-özel alanlar olan mahalle ve köylerde gündelik uğraşlar dolayısıyla, kentlerde ise mesire yeri, çarşı ve pazar gibi kalabalık ortamlarda flört etme fırsatı yakaladıklarını tespit eder (s. 150-155). 18. yüzyıla kadar üst sosyal tabakadan ve zengin kadınların hem kentlerde hem de kırsal alanlarda daha münzevî bir hayat yaşadıklarını dile getirir. Bunlara ek olarak Osmanlı kadınlarının toplumdan uzak yaşama kurallarını ihlal etmek için "salınarak yürüme”, "bakış” ve "sembolik dil kullanma" gibi farklı yöntemlere başvurduklarına değinir (s. 185-186). Sonuç olarak Osmanlı toplumunda hem kentsel hem de kırsal alanlarda kadınların ve erkeklerin sınırlı boyutta da olsa flört etme ve eğlenme fırsatı yakaladıklarına kanaat getirir.

Ebru Boyar ise “An Imagined Moral Community: Ottoman Female Public Presence, Honour and Marginality" (s. 187-229) başlıklı diğer bölümde toplum tarafından tasavvur edilen, sınırları belli olmayan, karmaşık bir sosyal kontrol sistemi olarak tanımladığı "hayalî ahlak toplulukları"nın topluma ahlakî normları empoze etmekle ve toplumun namusunu kadınların namusu üzerinden korumakla mükellef olduğunu ileri sürer. Buna göre kolektif namus bilinci "hayalî ahlak toplulukları"nın diğer insanların mahremi olmayan kişilerle ilişkisine müdahale etme tutumlarını meşrulaştırır (s. 187-188). Fetva ve kanunnamelerde namuslu ve iffetli kadınları tanımlamak için kullanılan muhaddere kavramına genişçe yer ayıran Boyar, bu kavramın açık biçimde tanımlanmamış olduğunu, farklı dönemlere ait fetvalardan yola çıkarak dönemine göre anlamı daralan ya da genişleyen bir kavram olduğunu, buna bağlı olarak namuslu ve iffetli olmanın sınırlarının döneme ve bölgeye göre değişebildiğini ortaya koyar. Bir minyatürden yola çıkarak 16. yüzyılda Bağdat'taki kadınların bir camide imamı yüzleri örtüsüzken dinlediklerini belirtir. Yine Gelibolulu Mustafa Ali'nin Kahire'de ayanların eşleri arasından bazı kadınların eşeğe bindiklerini görünce yaşadığı şaşkınlığı aktarır. Çünkü bu o dönem için Anadolu'da kınanan bir durumdur (s. 191-195). Çalışmasında sıkça atıfta bulunduğu makbul marjinallik kavramı çerçevesinde Osmanlı toplumunda bazı kadınların daha esnek bir hareket alanına sahip oldukları görüşünü gerekçelendirir. 16. yüzyılın sonlarında kadın dansçı ve şarkıcıların erkeklerin de bulunduğu ortamlarda mesleklerini icra edebildiklerini ve 19. yüzyılın sonlarında İstanbul'da çingene kadınların yüzlerini örtmeden dolaşabildiklerini belirtir (s. 198-201).

Bu bölümün ilerleyen kısımlarında Boyar, kefalet sistemiyle birbirlerinden mesul tutulan mahalle sakinlerinin başka erkeklerle gönül eğlendiren kadınları kadıya şikâyet edip başka mahalleye sürülmelerini istediklerine dair örnekler sunar. Dahası mahalle sakinlerinin ahlaka uygun olmayan davranışlarından şüphelendikleri kişilerin evlerine baskın düzenleyebildikle- 
rinden söz eder (s. 202-204). Aslında bu baskın mekanizmasının varlığı "mahallenin onuru" söz konusu olduğunda kamusal-özel alan ayrımının nasıl çözüldüğünü de gösterir. Fuhşun yasallaşması sürecinden bahsederken Osmanlı Devleti'nin fuhşa karşı tutumunun sistematik olmadığından ve sadece doğrudan devletin otoritesi için bir tehdit unsuruna dönüştüğünde müdahalede bulunulduğundan söz eder (s. 225-229). Boyar'ın çalışmasına göre ilginç olan şu ki, devlet politikasındaki değişikliklere ve profesyonel fuhşun resmen tanınmasına rağmen "hayalî ahlak toplulukları" kadınların ahlakî durumlarına odaklanmayı ve saygınlığın sınırlarını belirlemeyi sürdürür.

Yine Boyar'ın kaleme aldığı “The Public Presence and Political Visibility of Ottoman Women" (s. 230-252) başlıklı son bölümde Osmanlı kadınlarının siyasi alandaki varlıkları hem siyasetin nesneleri hem de değişim için kampanyalar düzenleyen ve istemedikleri koşulları protesto eden siyasi özneler olarak iki boyutta değerlendirilir. Bilindiği gibi hanedan kadınları siyasetin bileşenlerinden biri olarak imparatorluğun yürüttüğü yüksek politikalar üzerinde doğrudan etkiye sahipken; daha düşük sosyal tabakadan gelen kadınlar devlete arzuhal sunarak ya da kamusal eylemlere katılarak haklarını arayagelmişlerdir. Boyar'ın buradaki temel argümanı ise geç dönem Osmanlı'da değişen siyasi atmosferin, özellikle parlamentarizm ve anayasal hükümet gibi yeni siyasal fikirlerin yükselişinin kadınların Osmanlı toplumundaki siyasî varlıklarını güçlendirdiği şeklindedir. Boyar'a göre 19. yüzyıl Osmanlı kadınlarının siyasete katılımları açısından bir kırılma dönemidir. Bu dönemde kadınların daha çok politikleştiği ve erkekler kadar olmasa da yeni siyasî mekanizmaya katılmaya başladıkları görülür. Osmanlı İmparatorluğu'nun son dönemlerindeki savaşlar, göçler ve isyanlar kadınları siyaset sahnesine iterek daha aktif rol almalarının ve kadınların siyasete katılımının toplumun daha geniş kesimi tarafından kabul görmesinin yolunu açar (s. 240-243).

Sonuç olarak, Osmanlı topraklarında yaşayan kadınların kamusal alandaki varlığı ve görünürlüğü meselesini herhangi bir dönem veya bölge sınırlamasına gidilmeksizin geniş çerçevede inceleyen bu çalışmada, Osmanlı toplumundaki kadınları pasiflikle özdeşleştiren ve evlerine hapsedilmiş olarak karikatürize eden geleneksel ve Avrupamerkezci diyebileceğimiz bakış açılarının dışına çıkıldığı görülüyor. Ekonomik ve siyasal aktörler, köleler, tüketiciler, fakir veya varlıklı, elit veya alt sosyal tabakadan olmak üzere çeşitli rollerde ve statülerde ele alınan Osmanlı kadınlarının kamusal alanda aktif yer aldıklarının ve gündelik hayatın önemli birer parçası olduklarının ortaya konulması açısından eser literatüre önemli bir katkıda bulunuyor. 